\title{
Thermal Modeling of an Empty Greenhouse for Subtropics
}

\author{
Debaditya Gupta ${ }^{*}$, K.N. Tiwari and D.T. Santosh \\ Indian Institute of Technology, Kharagpur, West Bengal, India \\ *Corresponding author
}

\section{A B S T R A C T}

\begin{tabular}{|l|}
\hline Ke y w o r d s \\
Sawtooth shape \\
greenhouse, \\
Projected area, \\
Temperature \\
\hline Article Info \\
\hline $\begin{array}{l}\text { Accepted: } \\
\text { 07 October } 2019 \\
\text { Available Online: } \\
\text { 10 November } 2019\end{array}$ \\
\hline
\end{tabular}

\section{Keywords}

Sawtooth shape greenhouse, Projected area, Temperature

Article Info

Accepted:

Available Online:

\section{Introduction}

A greenhouse is a structure, which provides the most suitable microclimate for the maximum plant growth during the off-season (Sethi, 2009). The inside air temperature of a greenhouse directly depends upon the ambient air temperature, the solar radiation intensity, the overall heat transfer coefficient, the cover material and the wind velocity (Sethi and Sharma, 2007) and also upon the outside relative humidity, inside soil temperature, size and shape of greenhouse, location of greenhouse, ventilation rate and percentage of shading. Thermal analysis based on ventilation was done by Papadakis et al., (1996) to measure the air exchange rate inside the greenhouse and by Demrati et al., (2001) for multi-span Canarian type of plastic greenhouse to predict inside temperature in Morocco. Thermal modeling based on heat and mass transfer was done by Fatnassi et al., (2004) for a ventilated tunnel which was valid for the low-temperature difference.

A heat transfer based model was developed by Singh et al., (2006) for tomato crops for zero inside and fixed outside wind speed conditions to predict the temperature of the inside air, canopy, and cladding material of the greenhouse. Temperature and solar radiation based dynamic model was developed by 
Kumar et al., (2009) using a genetic algorithm technique for Gerbera crop at Kharagpur to predict inside temperature, canopy temperature, inside vapor pressure of the greenhouse. The present study deals with the development of a thermal model for prediction of inside temperature of the Sawtooth type greenhouse for different ventilation percentages and different shading percentages for Indian sub tropic conditions.

\section{Materials and Methods}

\section{Development of the thermal model}

This thermal model development includes the thermodynamic expressions and heat energy balance equations ventilation heat removal between the greenhouse to the external atmosphere, heat inflow and outflow between the greenhouse and the floor of the greenhouse.

\section{Energy balance of the greenhouse surface}

Rate of thermal energy received by the surface of the greenhouse $=$ Rate of thermal energy loss from the surface to the air inside the greenhouse by convection + Rate of thermal energy loss from the surface to ground through conduction and convection process.

$\alpha_{g}(1-\rho) \tau S_{t}$

$=h_{a} A_{g}\left(T_{z=0}-T_{i}\right)+h_{b} A_{g}\left(T_{z=0}-T_{0}\right) \ldots(1)$

Where,

$\rho=$ Reflectivity of the greenhouse covers (Dimensionless)

$\alpha_{g}=$ Absorptivity of the soil inside the greenhouse (Dimensionless)

$h_{\mathrm{a}}=$ Convective heat transfer coefficient between the greenhouse floor and the air inside the greenhouse, $\left(\mathrm{W} / \mathrm{m}^{2} \mathrm{~K}\right)$ $h_{b}=$ Bottom heat transfer coefficient between the greenhouse floor and ground beneath $\left(\mathrm{W} / \mathrm{m}^{2} \mathrm{~K}\right)$

$\tau=$ Transmissivity of the greenhouse cover, (Dimensionless)

$A_{g}=$ Floor area of the sawtooth shape greenhouse $\left(\mathrm{m}^{2}\right)$

$T_{z=0}=$ Temperature of the greenhouse floor $\left({ }^{0} \mathrm{C}\right)$

$T_{i}=$ Temperature of the inside air of the greenhouse $\left({ }^{0} \mathrm{C}\right)$

$T_{0}=$ Temperature of the soil beneath the greenhouse $\left({ }^{0} \mathrm{C}\right)$

$S_{t}=$ Solar radiation comes to the greenhouse (W)

Energy balance of the inside air of the greenhouse

Rate of energy transferred from the ground surface to the inside air + Rate of energy transmitted in the greenhouse which is unused by the ground and cover + Rate of energy reflected from the cover $=$ Rate of total energy loss from the greenhouse cover + Rate of energy loss through the door + Rate of energy loss through ventilation

$$
\begin{aligned}
h_{a} A_{g}\left(T_{z}=0\right. & \left.-T_{i}\right)+\left(1-\alpha_{g}\right)(1-\rho) \tau S_{t}+\rho \tau S_{t} \\
& =U_{t} A_{c}\left(T_{i}-T_{a}\right)+h_{d} A_{d}\left(T_{i}-T_{a}\right)+E_{v} \ldots
\end{aligned}
$$

$h_{d}=$ Convective heat transfer coefficient between the greenhouse door and the ambient air, $\left(\mathrm{W} / \mathrm{m}^{2} \mathrm{~K}\right)$

$U_{t}=$ Overall heat transfer coefficient for the greenhouse to the ambient air, $\left(\mathrm{W} / \mathrm{m}^{2} \mathrm{~K}\right)$

$T_{a}=$ Temperature outside the greenhouse $\left({ }^{0} \mathrm{C}\right)$

$A_{d}=$ Area of the door of the greenhouse $\left(\mathrm{m}^{2}\right)$ 
$A_{c}=$ Total area of the greenhouse cover $\theta=$ east-west vertical angle (degree) surface $\left(\mathrm{m}^{2}\right)$

Rearranging equations (1) and (2), we get

$$
\begin{aligned}
& \theta=\tan ^{-1}\left(\frac{-\cot (90-\beta)}{\cos \gamma}\right) \\
& \beta=\text { altitude angle (degree) } \\
& \gamma=\text { solar azimuth angle (degree) } \\
& \beta=\sin ^{-1}(\cos \varphi \cos \delta \cos \omega+\sin \varphi \sin \delta) \ldots(1
\end{aligned}
$$

$$
T_{i}=\frac{\begin{array}{l}
\left.\frac{h_{a}}{h_{a}+h_{b}} \alpha_{g}(1-\rho)+\left\{\left(1-\alpha_{g}\right)(1-\rho)+\rho\right\}\right] \\
S_{t}+\frac{h_{a} h_{b}}{h_{a}+h_{b}} A_{g} T_{0}+\left(U_{t} A_{c}+h_{d} A_{d}\right) T_{a}-E_{v}
\end{array}}{U_{t} A_{c}+h_{d} A_{d}+h_{a} A_{g}-\frac{h_{a}^{2} A_{g}}{h_{a}+h_{b}}} \ldots
$$

$0)$

\section{Calculations for the thermal model}

Projected area (Singh et al., (2006)) calculation for Sawtooth type greenhouse (Fig. $1)$.

Let $s_{t}$ be the actual solar radiation incident upon a unit area of the greenhouse

The actual solar radiation incoming to the greenhouse is given by,

$S_{t}=s_{t} \cdot A \cdot(1-x)$

$x=$ shading fraction

$$
\gamma=\cos ^{-1}\left(\frac{\sin \beta \sin \varphi-\sin \delta}{\cos \beta \cos \varphi}\right)
$$

$\delta=23.5 \sin \left\{\frac{2 \pi}{365}\left(284+n_{d}\right)\right\}$

$\omega=15^{0}(S T-12)$

$S T=$ Standard local time

$\delta=$ declination, $($ degree $)$

$\omega=$ hour angle (degree)

Let, $\mathrm{A}$ is the projected area of the greenhouse, then

$A=A_{1}+A_{2} \ldots(5)$

Where, $A_{1}=y_{1} \cdot L$ and $A_{2}=y_{2}, L \ldots(6)$

$y_{1}=W \cdot|\sin \theta|$

$y_{2}=H \cdot|\cos \theta|$

$W=$ width of the greenhouse floor $(\mathrm{m})$

$H=$ height of the greenhouse from the floor to the bottom of the roof truss or the gutter height (m)

$L=$ the length of the greenhouse (which is perpendicular to the plane of the paper) (m)

$n_{d}=$ Day in a year, $\left(\mathrm{n}_{\mathrm{d}}=1,2 \ldots 365 / 366\right.$ for $1^{\text {st }}$ January to $31^{\text {st }}$ December, i.e. $\mathrm{n}_{\mathrm{d}}=1$ for $1^{\text {st }}$ January and $365 / 366$ for $31^{\text {st }}$ December)

\section{Ventilation heat removal}

Ventilation heat removal is occurred due to the action of the wind force effect and stack effect (buoyancy effect).

The total ventilation flow rate of wind is the resultant of these two effects (Ganguly and Ghosh, 2009)

$Q_{\text {vent }}=\sqrt{Q_{\text {wind }}^{2}+Q_{\text {stack }}^{2}} \ldots$

$Q_{\text {wind }}=c_{d} c_{w}^{0.5} A_{e f f} u \ldots(15)$ 
$Q_{\text {stack }}=A_{\text {eff }} \sqrt{2 g H\left(\frac{T_{i}-T_{a}}{T_{a}}\right)}$

Therefore the total ventilation flow rate is given by

$Q_{v e n t}=c_{d} A_{\text {eff }} \sqrt{c_{w} u^{2}+2 g h\left(\frac{T_{i}-T_{a}}{T_{a}}\right)} \ldots$

$A_{\text {eff }}=\frac{A_{\text {roof }} A_{\text {side }}}{\sqrt{A_{\text {roof }}^{2}+A_{\text {side }}^{2}}}$

$T_{i}=$ Inside air temperature (absolute temperature in $\mathrm{K}$ )

$T_{a}=$ Outside air temperature (absolute temperature in $\mathrm{K}$ )

$u=$ wind speed $(\mathrm{m} / \mathrm{s})$

$A_{\text {eff }}=$ effective area of ventilation $\left(\mathrm{m}^{2}\right)$

Computational procedure for the thermal model development (Fig. 2)

\section{Study area description}

The study area is located at the Indian Institute of Technology Kharagpur campus which has a geographical location of $22.346^{\circ}$ North latitude and $87.231^{\circ}$ East longitude and an average elevation of $61 \mathrm{~m}$.

\section{Data collection for the thermal model}

The outside temperature data outside the greenhouse, soil temperature inside the greenhouse at $30 \mathrm{~cm}$ depth, are collected from the Precision Farming Development Centre, Agricultural and Food Engineering Department, Indian Institute of Technology, Kharagpur. From $1^{\text {st }}$ August to $27^{\text {th }}$ October 2017. Wind speed inside the greenhouse is taken from NASA POWER site that is https://www.larc.nasa.gov/cgi-bin/agro.cgi and Solar radiation data outside the greenhouse is taken from https://www.meteocontrol.com.

Solutions procedure for the thermal model

Determination of the values of the heat transfer coefficients

Convection heat transfer coefficient determination (Tiwari and Goyal, 1998)

$h=2.8+3 v$

$h=$ Convective heat transfer coefficient $\left(\mathrm{w} / \mathrm{m}^{2}\right)$

$v=$ Wind velocity $(\mathrm{m} / \mathrm{s})$

Velocity inside the greenhouse was measured using an instantaneous anemometer and it is found that it is between 0.09 to $0.22 \mathrm{~m} / \mathrm{s}$, so the inside velocity of the greenhouse was taken as $0.15 \mathrm{~m} / \mathrm{s}$.

Therefore $h_{\alpha}=3.25 \mathrm{~W} / \mathrm{m}^{2} \mathrm{~K}$ and hot air is also entering from the door, hence for door $h_{d}=2.8+3 v_{\text {out }}$, where $v_{\text {out }}$ is the outside wind velocity in $(\mathrm{m} / \mathrm{s})$

Overall heat transfer coefficient is estimated by equation (20)

$U_{t}=\frac{1}{\frac{1}{h_{a}}+\frac{\Delta x}{k}+\frac{1}{h_{0}} \ldots}$

$\Delta x=$ Thickness of plastic film $(200 \mu \mathrm{m})$

$k=$ Thermal conductivity of plastic film (0.3 $\mathrm{W} / \mathrm{mK}$ ) https://www.engineeringtoolbox.com)

From the sieve analysis of the dry soil sample taken away from the greenhouse (up to $30 \mathrm{~cm}$ 
depth) it is found that it consist of $14.845 \%$ of coarse sand $(0.25 \mathrm{~W} / \mathrm{mK}), 19.73 \%$ of medium sand $(0.27 \mathrm{w} / \mathrm{mK}), 38.92 \%$ of fine sand $(0.15$ $\mathrm{W} / \mathrm{mK}), 19.147 \%$ sandy clay $(1.61 \mathrm{~W} / \mathrm{mK})$ and $7.357 \%$ silty clay loam $(1.09 \mathrm{~W} / \mathrm{mK})$ (Warrick, 2001). Hence the value of bottom heat transfer coefficient is found as

$h_{b}=\frac{K}{z}=\frac{\sum \frac{K_{i} P_{i}}{100}}{0.03}$.

Where, $z=0.03 \mathrm{~m}$ soil depth and $K_{i}$ and $P_{i}$ are respectively the thermal conductivity and percentage of that particle in that soil.

$h_{b}=1.8 \mathrm{~W} / \mathrm{m}^{2} \mathrm{~K}$

The values of $\alpha_{g}, \rho$, and $\tau$ are taken as 0.8 , 0.15, 0.65 respectively (Deshmukh, 2005)

\section{Assumptions of the thermal model}

The greenhouse is a Sawtooth type greenhouse.

There is no plant inside the greenhouse.

No chemical reaction inside the greenhouse air takes place.

No temperature and moisture gradient exist in the air.

Solar heat flux variation for a day is negligible.

No fogger, fan and heat pump is used for heat removal.

Steady-state condition.

Heat storage term for cover, structural material, and floor and inside air are neglected

\section{The solution of the thermal model}

The thermal model developed is solved by the Newton Raphson Iteration technique using
MATLAB 2017a software. The model inputs are outside temperature, soil temperature, solar radiation, wind speed. The model starts with an assumed initial value of inside temperature and gives a final value of inside temperature. Where $T_{a}, T_{i}, T_{\text {soil }}$ are outside temperature or ambient temperature, inside temperature, soil temperature, $S_{t}$ is the solar radiation and $v_{\text {wind }}$ is the wind velocity respectively. The model was simulated by changing the shading percentage and ventilation percentage.

\section{Performance evaluation of the thermal model}

The performance evaluation of the thermal model was tested by the Nash-Sutcliffe Efficiency (NSE) and Coefficient of Determination $\left(\mathrm{R}^{2}\right)$

$N S E=1-\frac{\sum_{i=1}^{n}\left(T_{o i}-T_{p i}\right)^{2}}{\sum_{i=1}^{n}\left(h_{o i}-\overline{h_{o}}\right)^{2}}$.

$R^{2}=\left[\frac{\sum_{i=1}^{n}\left[\left(T_{i}-\overline{T_{p}}\right)\left(T_{o i}-\overline{T_{o}}\right)\right]}{\sqrt{\left[\left(\sum_{i=1}^{n}\left(T_{p i}-\overline{T_{p}}\right)^{2}\right)\left(\sum_{i=1}^{n}\left(T_{o i}-\overline{T_{o}}\right)^{2}\right)\right]}}\right]^{2}$

Where,

$T_{o i}=$ observed value of temperature

$T_{p i}=$ predicted value of temperature

$\overline{T_{o}}=$ observed mean of temperature

$\overline{T_{p}}=$ predicted mean of temperature

\section{Results and Discussion}

Thermal analysis for greenhouse inside temperature

The model was simulated using a different percentage of shadings. The percentage of shadings is also known as shading fractions. 
Table. 1 The NSE values and $\mathrm{R}^{2}$ values of the thermal model for different shading percentages and different ventilation conditions

\begin{tabular}{|c|c|c|c|}
\hline Percentage Shading & Percentage ventilation & NSE & $\mathbf{R}^{\mathbf{2}}$ \\
\hline $\mathbf{0}$ & 0 & -38.78 & 0.4 \\
\hline & 10 & 0.49 & 0.6 \\
\hline & 20 & 0.33 & 0.48 \\
\hline $\mathbf{2 5}$ & 30 & 0.21 & 0.44 \\
\hline & 0 & -20.43 & 0.43 \\
\hline & 10 & 0.55 & 0.59 \\
\hline & 20 & 0.16 & 0.41 \\
\hline $\mathbf{5 0}$ & 30 & 0.1 & 0.40 \\
\hline & 0 & -7.82 & 0.49 \\
\hline & 10 & 0.47 & 0.56 \\
\hline & 20 & 0.14 & 0.41 \\
\hline & 30 & -0.02 & 0.37 \\
\hline & 0 & -0.96 & 0.55 \\
\hline & 10 & 0.24 & 0.48 \\
\hline & 20 & -0.07 & 0.36 \\
\hline & 30 & -0.24 & 0.32 \\
\hline & 0 & -0.28 & 0.55 \\
\hline & 10 & 0.2 & 0.43 \\
\hline & 20 & -0.2 & 0.32 \\
\hline & 30 & -0.27 & 0.31 \\
\hline
\end{tabular}

Fig.1 Line diagram of the greenhouse projected area of the greenhouse (Front View)

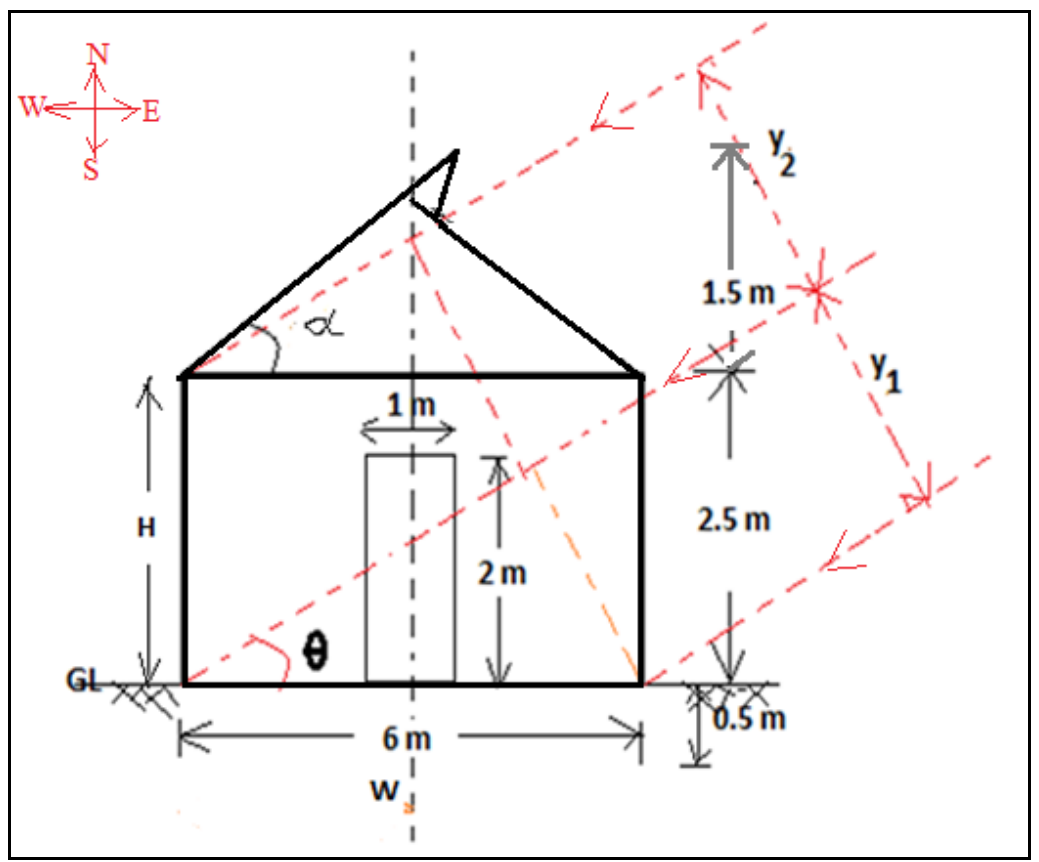


Fig.2 Flow chart of the thermal model solution

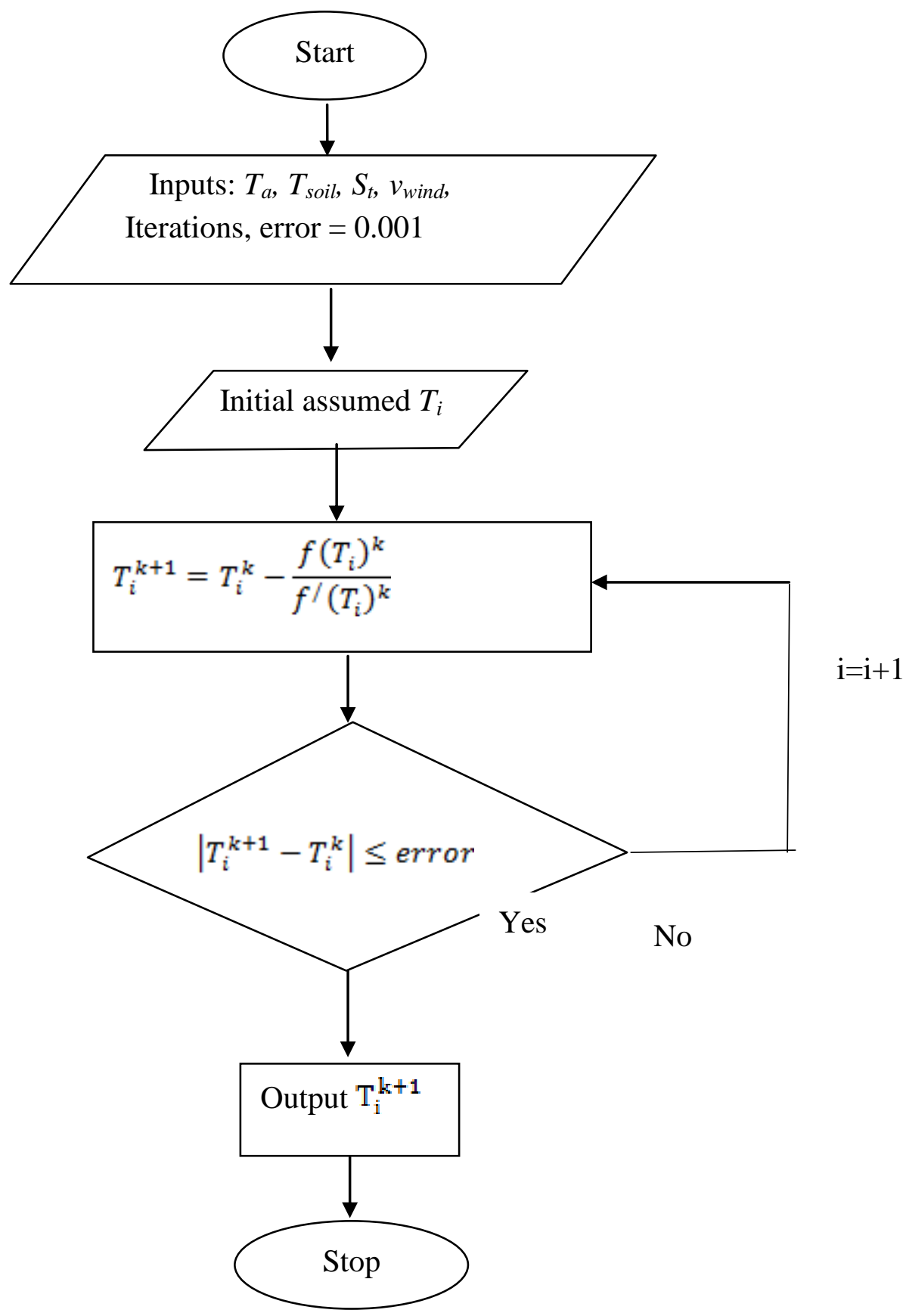


Fig.3 Variation of actual inside temperature, outside temperature, and the model predicted inside temperature for no shade net condition for $0,10,20,30$ percent ventilation with days $\left(1^{\text {st }}\right.$ August to $27^{\text {th }}$ October 2017)

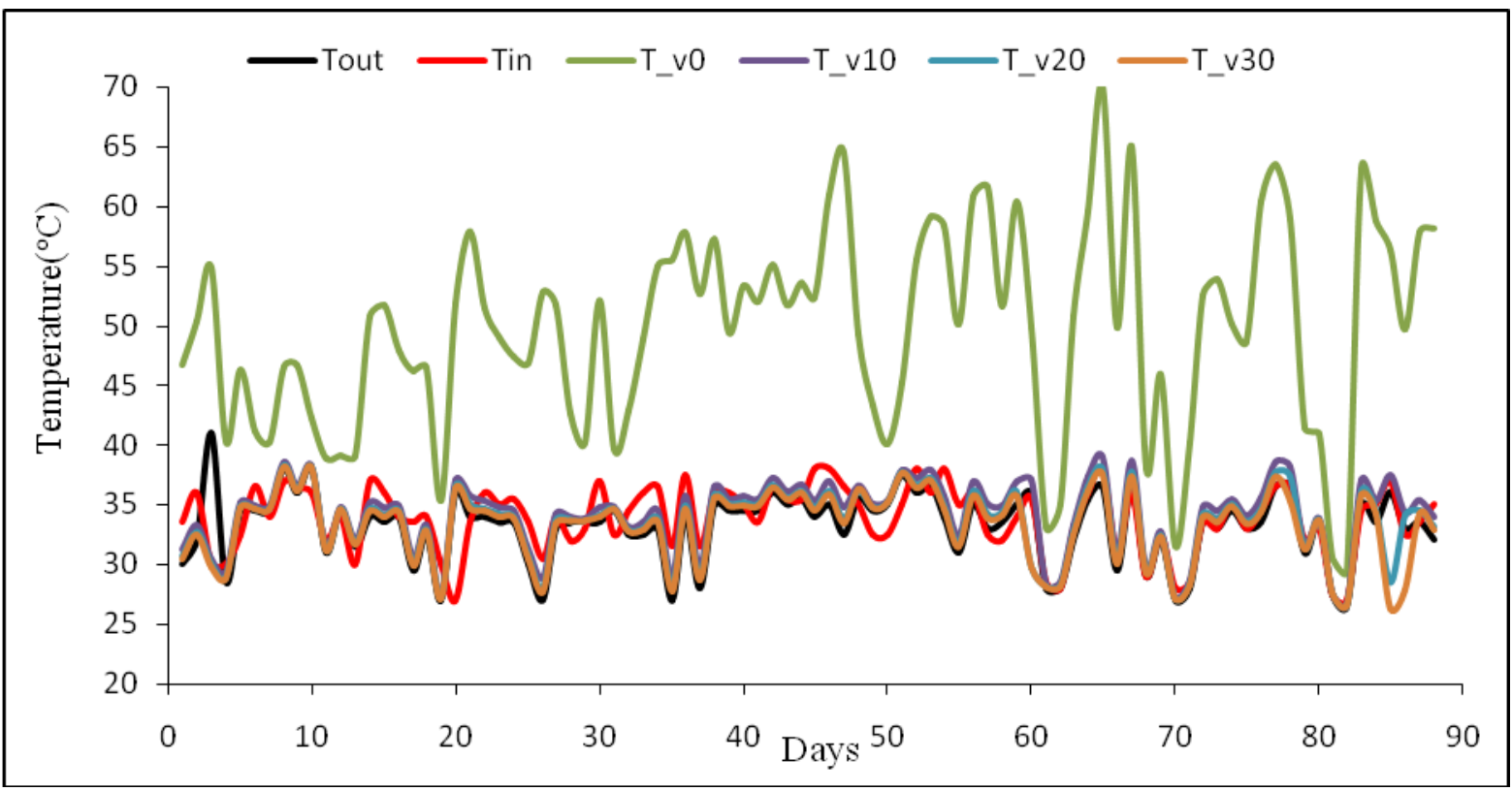

Fig.4 Variation of actual inside temperature, outside temperature, and the model predicted inside temperature for $25 \%$ shade net conditions for $0,10,20,30$ percent ventilation with days $\left(1^{\text {st }}\right.$ August to $27^{\text {th }}$ October 2017)

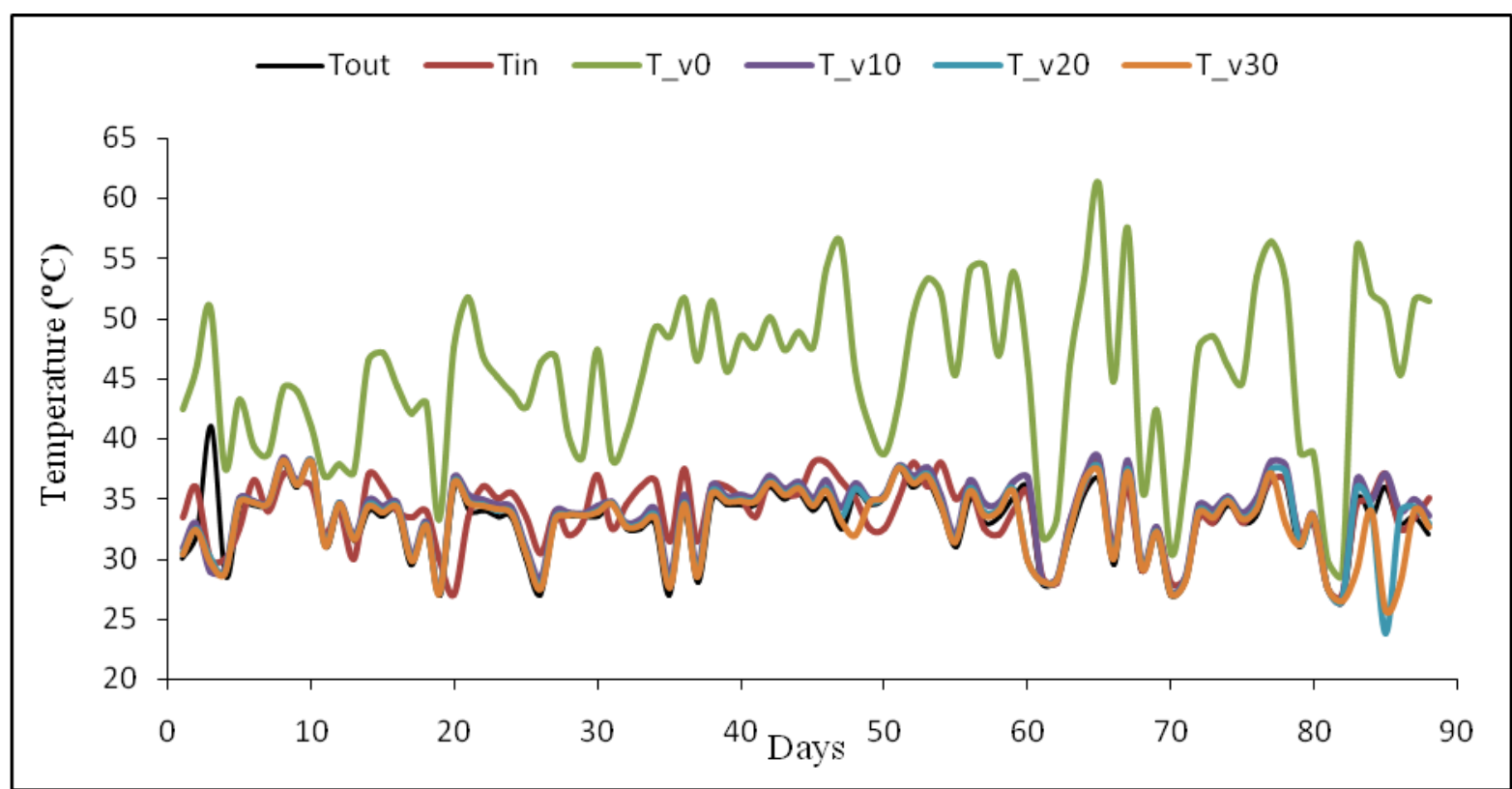


Fig.5 Variation of actual inside temperature, outside temperature, and the model predicted inside temperature for $50 \%$ shade net condition for $0,10,20,30$ percent ventilation with days $\left(1^{\text {st }}\right.$

\section{August to $27^{\text {th }}$ October 2017)}

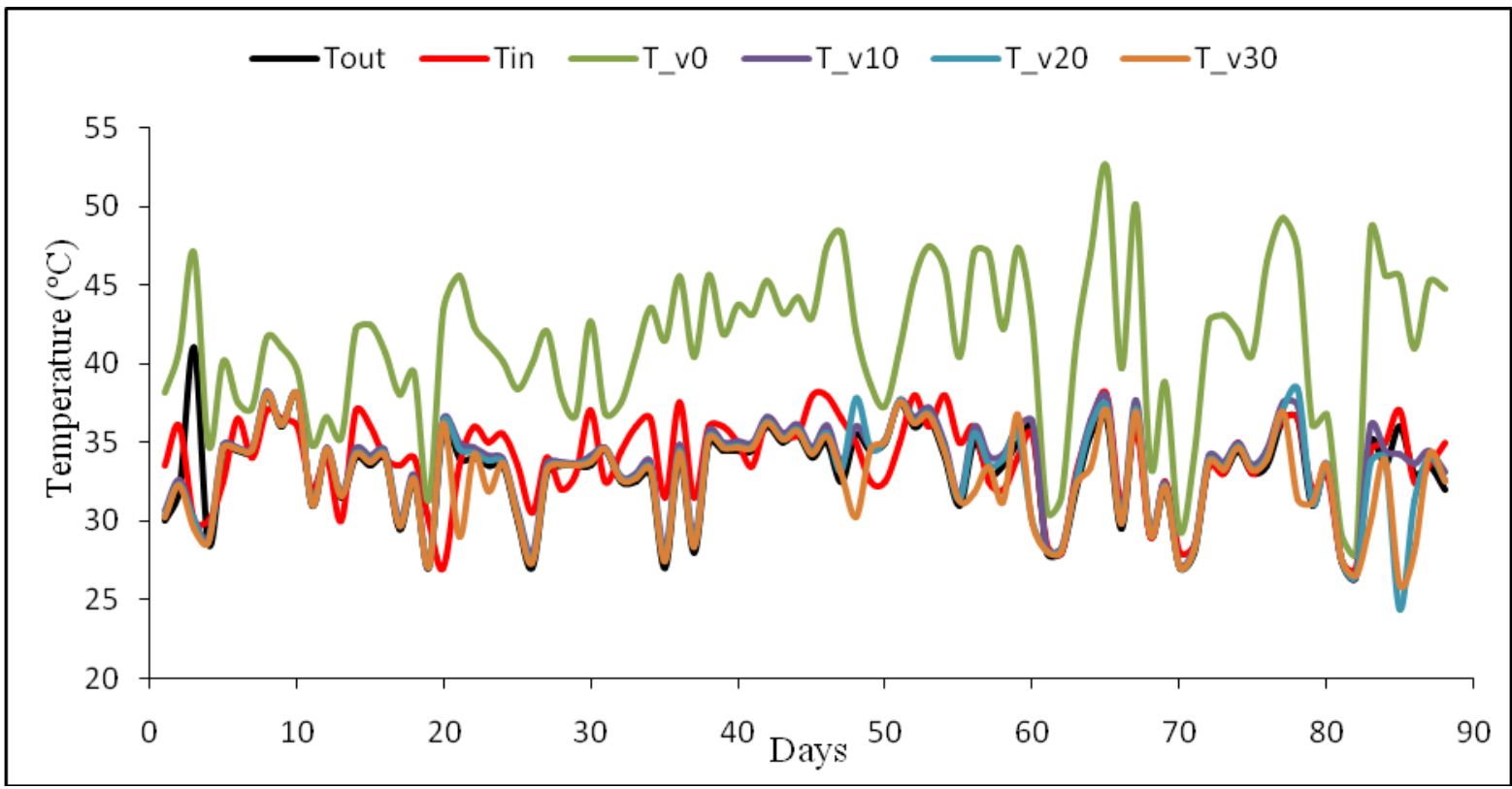

Fig.6 Variation of actual inside temperature, outside temperature, and the model predicted inside temperature for $75 \%$ shade net condition for $0,10,20,30$ percent ventilation with days $\left(1^{\text {st }}\right.$ August to $27^{\text {th }}$ October 2017)

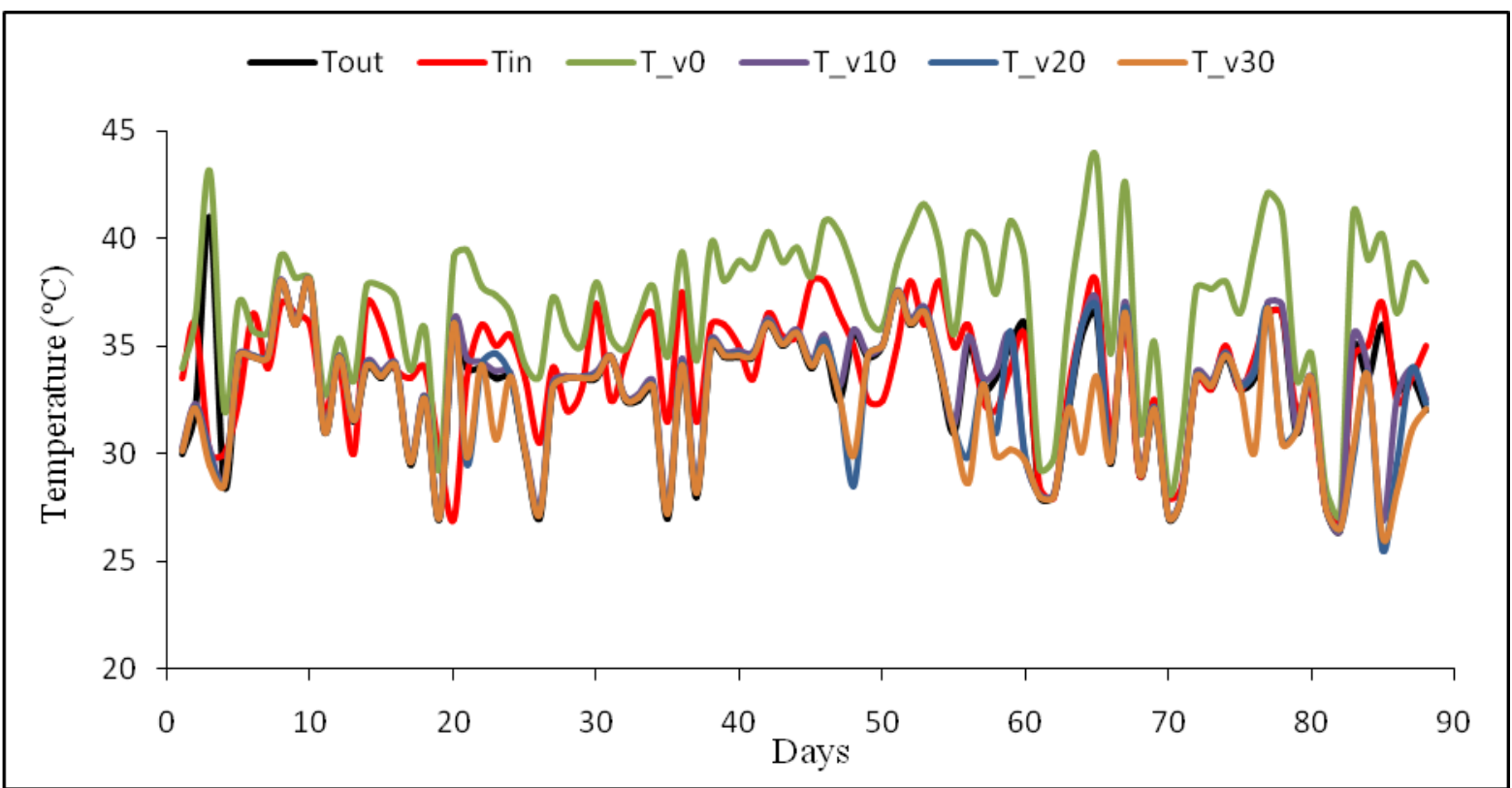


Fig.7 Variation of actual inside temperature, outside temperature with the model predicted inside temperature for $90 \%$ shade net condition for $0,10,20,30$ percent ventilation with days $\left(1^{\text {st }}\right.$

\section{August to $27^{\text {th }}$ October 2017)}

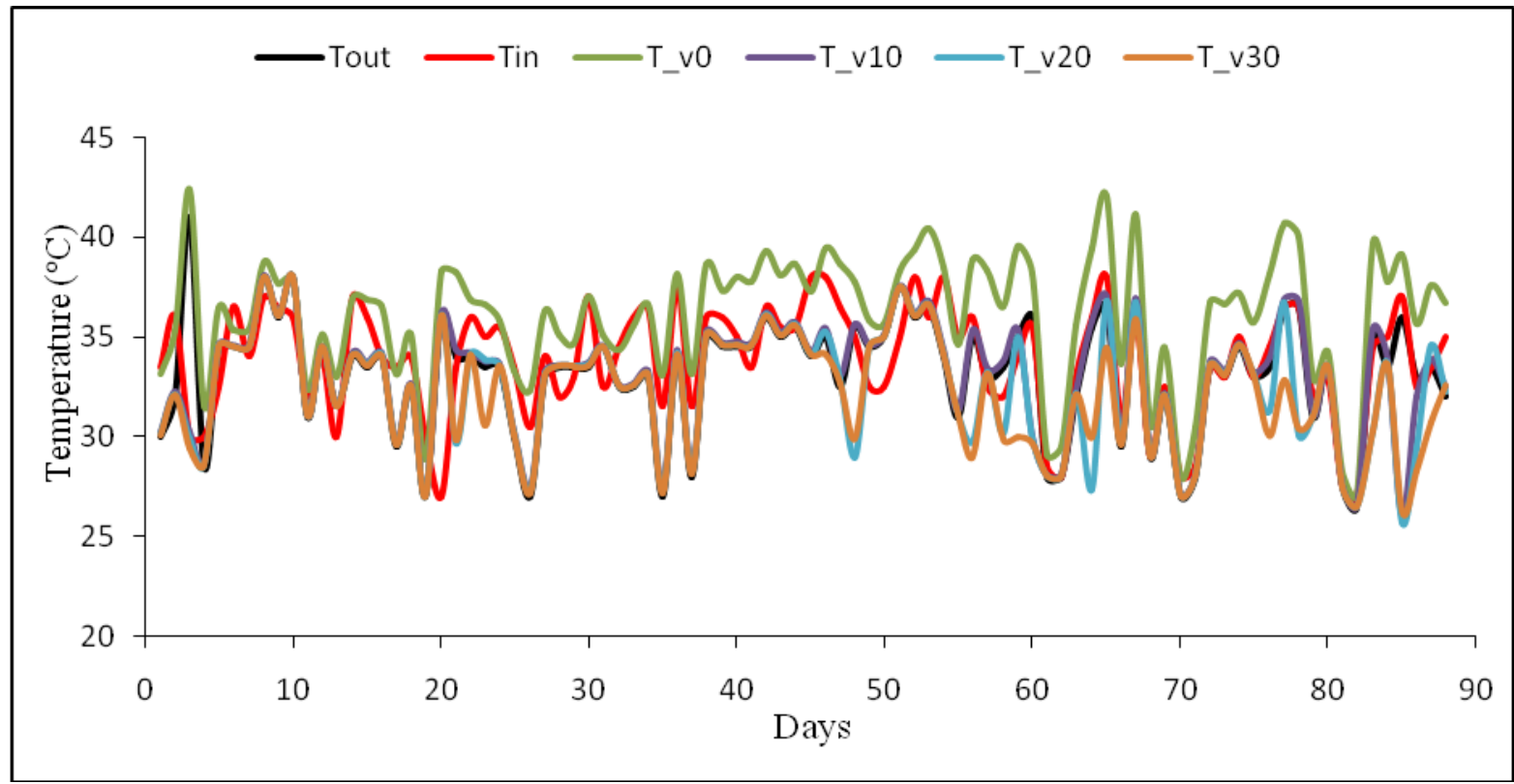

The shadings are provided because only the rest of the solar radiation can able to enter into the greenhouses. Here the model was simulated by taking no shading and $25 \%$, $50 \%, 75 \%$, and $90 \%$ shading percentage and for each shading percentage, the model was simulated by taking zero ventilation, $10 \%$ ventilation, $20 \%$ ventilation, $30 \%$ ventilation. The percentage of ventilation is the total percentage of ventilation (roof and side ventilation) concerning the greenhouse floor area. Here also one assumption is taken that the area of both the roof and side ventilation is the same). From the NSE and $\mathrm{R}^{2}$ values of the thermal model for different shading percentages and different ventilation conditions (Table 1), it is clear that the model which is calibrated by taking $10 \%$ ventilation and $25 \%$ shading percentage gives NSE value of 0.55. Again from the graphs (Fig. 3 to 7), it is clear that as the percentage of shading increases the amount of incident solar radiation decreases and this leads to the decrease in the inside temperature of the greenhouse. It is also seen from the figures that the lowest value of temperature is $25^{\circ} \mathrm{C}$ in case of $90 \%$ shade net and $20 \%$ ventilation condition and $30 \%$ ventilation conditions and it is also almost same for $75 \%$ shading conditions which indicates that temperature decreases up to a certain percentage of natural ventilation and a certain shading percentage. The worst value of NSE found to be -38.78 , this is due to the tremendous increase of inside temperature due to the combined effect of no ventilation and no shading condition, in this case, the temperature reaches $70^{\circ} \mathrm{C}$.

Thermal modeling is necessary for a greenhouse to predict the inside microclimatic condition and to understand the cooling or heating requirement in the greenhouse.

A MATLAB based program through mathematical equations was developed to predict the inside greenhouse temperature. The model was simulated for different shading and ventilation percentage for a Sawtooth shape greenhouse. Thermal analysis model efficiencies of the greenhouse, it is clear that 
the model which is simulated by taking $10 \%$ ventilation, and $25 \%$ shading percentages give the best model efficiency. The main cause of the lower model efficiency is due to the model assumptions. Therefore there is a scope to further model improvement by refining the model assumptions.

\section{References}

Demrati, H., Boulard T., Bekkaoui, A., Bouirden, L. 2001. Natural Ventilation and Microclimatic Performance of a Large-scale Banana Greenhouse. Journal of Agricultural Engineering Research, 80(3): 261-271.

Deshmukh A., A. 2005. Studies on microclimate variations in the naturally ventilated greenhouse for subtropics. M. tech thesis submitted to IIT Kharagpur, pp. 29

Ganguly, A. and Ghosh, S. 2009. Model development and experimental validation of floricultural greenhouse under natural ventilation. Energy and Buildings, 41(5): 521-527.

Kumar, K.S., Tiwari, K.N. and Jha, M.K. 2009. Design and technology for greenhouse cooling in tropical and subtropical countries: A review. Energy and Buildings, 41(12):12691275.
Papadakis, G., Mermier, M., Meneses, J. F., Boulard, T 1996. Measurement and Analysis of Air Exchange Rates in a Greenhouse with Continuous Roof and Side Openings. Journal of Agricultural Engineering Research, 63: 219 - 228.

Sethi, V. P. 2009. On the selection of shape and orientation of a greenhouse: Thermal modeling and experimental validation. Solar Energy, 83: 21-28, Elsevier.

Sethi, V.P., Sharma, S.K., 2007. Thermal modeling of a greenhouse integrated to an aquifer coupled-cavity flow heat exchanger system. Sol. Energy. 81 (6), 723-741.

Singh, G., Singh, P. P., Lubana, P. P. S., Singh K. G. 2006. Formulation and validation of a mathematical model of the microclimate of a greenhouse. Renewable energy, 31: 1541-1560, Elsevier.

Tiwari, G.N, Goyal, R. K. 1998. Greenhouse Technology. Narosa Publishing House, New Delhi.

Tiwari, G. N. Greenhouse Technology for controlled environment. Narosa Publishing House, pp. 203.

Warrick, A. W. 2001. Soil Physics Companion, CRC Press Book, ISBN 9780849308376.

\section{How to cite this article:}

Debaditya Gupta, K.N. Tiwari and Santosh, D.T. 2019. Thermal Modeling of an Empty Greenhouse for Subtropics. Int.J.Curr.Microbiol.App.Sci. 8(11): 753-763. doi: https://doi.org/10.20546/ijcmas.2019.811.089 